\title{
Effect of the Level of Irradiance on Growth and Content of Photosynthetic Pigments of Canadian Elodea (Elodea canadensis) in Model System "Water-Bottom Sediments"
}

\author{
Yuliyana V. Aleksandrova ${ }^{a}$, \\ Tatiana A. Zotina*a,b and Nikolay A. Gaevsky ${ }^{\mathrm{b}}$ \\ anstitute of Biophysics \\ FRC "Krasnoyarsk Science Center SB RAS” \\ Krasnoyarsk, Russian Federation \\ ${ }^{b}$ Siberian Federal University \\ Krasnoyarsk, Russian Federation
}

Received 27.03.2019, received in revised form 23.10.2019, accepted 25.12.2019, published online 30.04.2020

\begin{abstract}
Bioassays based on aquatic plants are a convenient tool for studying the quality of bottom sediments. One of the stages in the development of a bioassay is the selection of optimal growth conditions for indicator plants in a model test system. Response of indicator physiological endpoints of Canadian waterweed (Elodea canadensis) to light flux density was investigated to determine optimal irradiance level in a "water - sediment" model system, proposed previously for contact bioassay of natural bulk bottom sediments. Based on the response of shoot and root growth (length and weight), and concentration and ratio of photosynthetic pigments (chl. $a$, chl. $b$, and carotenoids) of Elodea to the change of light flux density, no limitation or inhibition of growth and photosynthesis of Elodea was revealed at light flux density from 56 to $143 \mu \mathrm{mol}$ quanta $\cdot \mathrm{m}^{-2} \cdot \mathrm{s}^{-1}$. Hence, the level of irradiance within this range can be recommended for use in the experimental system proposed for bioassay of bulk bottom sediments using E. canadensis as an indicator.
\end{abstract}

Keywords: bioassay, bottom sediment, aquatic plant, shoot length, root length, photosynthetic pigments, light saturation.

Citation: Aleksandrova Yu.V., Zotina T.A., Gaevsky N.A. Effect of the level of irradiance on growth and content of photosynthetic pigments of Canadian Elodea (Elodea canadensis) in model system "water-bottom sediments". J. Sib. Fed. Univ. Biol., 2020, 13(2), 188-196. DOI: 10.17516/1997-1389-0317

(C) Siberian Federal University. All rights reserved

This work is licensed under a Creative Commons Attribution-NonCommercial 4.0 International License (CC BY-NC 4.0).

* Corresponding author E-mail address: t_zotina@ibp.ru

ORCID: 0000-0002-4274-963X (Aleksandrova Yu.); 0000-0002-4792-1582 (Zotina T.); 0000-0002-3747-9858 (Gaevsky N.) 


\title{
Влияние светового фактора на рост \\ и содержание фотосинтетических пигментов \\ Элодеи канадской (Elodea canadensis) \\ в модельной системе «вода-донные отложения»
}

\author{
Ю.В. Александрова ${ }^{a}$ Т.А. Зотина ${ }^{a, \sigma}$, Н.А. Гаевскийб \\ ${ }^{a}$ Институт биофизики \\ ФИЦ «Красноярский научный изентр СО РАН» \\ Российская Федераџия, Красноярск \\ ${ }^{6}$ Сибирский федеральный университет \\ Российская Федерачия, Красноярск
}

\begin{abstract}
Аннотация. Биотесты на основе водных растений являются удобным инструментом для изучения качества донных отложений. Один из этапов разработки биотеста - подбор оптимальных условий для роста индикаторных растений в модельной тест-системе. В настоящей работе оценивалось влияние уровня освещенности на индикаторные физиологические показатели водного растения элодеи канадской (Elodea canadensis) с целью подбора оптимального уровня освещенности в модельной системе «вода-донные отложения», предложенной ранее для контактного тестирования цельных донных отложений. Анализ реакции показателей роста побегов и корней элодеи (длины и веса), а также содержания и соотношения фотосинтетических пигментов (хл. $a$, хл. $\sigma$, каротиноидов) на изменение уровня освещенности позволяет выделить диапазон светового потока от 56 до 143 мкмоль $\cdot$ м $^{-2} \cdot \mathrm{c}^{-1}$, в котором не происходит светового лимитирования и ингибирования роста и фотосинтеза элодеи канадской. Следовательно, уровень освещенности из выделенного диапазона рекомендуется использовать в модельной системе, предложенной для биотестирования донных отложений с использованием элодеи канадской в качестве индикатора.
\end{abstract}

Ключевые слова: биотестирование, донные отложения, водное растение, длина побега, длина корня, фотосинтетические пигменты, световое насыщение.

Цитирование: Александрова, Ю.В. Влияние светового фактора на рост и содержание фотосинтетических пигментов элодеи канадской (Elodea canadensis) в модельной системе «вода-донные отложения» / Ю.В. Александрова, Т.А. Зотина, Н.А. Гаевский // Журн. Сиб. федер. ун-та. Биология, 2020. 13(2). С. 188-196. DOI: 10.17516/1997-1389-0317

\section{Введение}

Элодея канадская (Elodea canadensis Michx.) - инвазивный вид, натурализовавшийся в пресных водоемах Евразии, в том числе в р. Енисей (Зотина, 2013; 2014). E. canadensis широко используется как индикатор техногенного загрязнения природных водоемов (Samec-
ka-Cymerman, Kempers, 2003; Болсуновский и др., 2007; Krems et al., 2013; Muratova et al., 2014; Medvedeva et al., 2014), а также для целей биотестирования (Girling et al., 2000; Knauer et al., 2006; McGregor et al., 2008; Arts et al., 2008; Brain et al., 2012; Zotina et al., 2014; 2015; Koca et al., 2018). Ранее нами была предложена мо- 
дельная система для контактного тестирования природных цельных донных отложений с использованием элодеи канадской в качестве индикаторного вида (Zotina et al., 2014; 2015). Индикаторные показатели элодеи канадской (длина побегов, длина корней, вес побегов, содержание хлорофилла) проявляют разную чувствительность к токсикантам и характеризуются разной вариабельностью (Arts et al., 2008; Brain et al., 2012; Zotina et al., 2015). Как фототрофный организм, элодея канадская чувствительна к качественным (спектральному составу) и количественным (уровню освещенности, фотопериоду) характеристикам света, что проявляется в изменении показателей ее роста и фотосинтеза (Lichtenthaler et al., 1981; Wolff, Senger, 1991; Madsen, Sand-Jensen, 1994; Riis et al., 2012; Eller et al., 2015). Поэтому в данной работе исследовалась зависимость физиологических параметров элодеи канадской (показателей роста побегов и корней, содержания фотосинтетических пигментов в побегах) от уровня освещенности с целью подбора оптимального светового режима для растения в модельной системе «вода-донные отложения», предложенной нами ранее для контактного биотестирования цельных донных отложений.

\section{Материалы и методы}

Побеги элодеи канадской отбирали в p. Енисей в сентябре со стороны левого берега, на 13,5 км выше речного вокзала г. Красноярска, одновременно была отобрана проба воды для химического анализа. Растения были привезены в лабораторию и акклиматизировались в емкости объемом 40 л, наполненной водопроводной водой комнатной температуры $\left(22-23{ }^{\circ} \mathrm{C}\right)$, при освещении люминесцентными лампами холодного белого спектра в течение 16 часов в сутки при уровне поверхностной освещенности около 4 кЛк. Растения ежеднев- но перемешивали, воду меняли по мере необходимости. Для эксперимента брали апикальные побеги длиной 4 см одинаковые по форме и размеру листьев, отросшие в лаборатории. Для первого эксперимента использовали растения после акклиматизации в течение 8 суток, для второго - после 25 суток. Средний сухой вес побега элодеи в начале первого эксперимента составлял 0,021 $\pm 0,003$ г, в начале второго - 0,014 $\pm 0,004$ г. В качестве субстрата использовали искусственные донные отложения (ДО), приготовленные по протоколу Организации экономического сотрудничества и развития (OECD, Guidline 219), как описано нами ранее (Zotina et al., 2015). В стеклянные стаканы объемом 650 мл, диаметром 6,5 см помещали по 260 г сырых ДО, объем которых составлял около 150 мл, присыпали крупным песком. Поверх ДО наливали 450 мл водопроводной воды, отфильтрованной через мембраны с диаметром пор 0,22 мкм (45 мм диам., GSWP, Millipore). Воду наливали по пластиковому шпателю, чтобы минимизировать взмучивание ДО. Через сутки в ДО высаживали побеги элодеи канадской по 7 штук на стакан, на равном расстоянии друг от друга по периметру, с помощью стеклянной палочки. Дистальную часть побегов помещали в субстрат на глубину около 1 см. Перед высадкой растений величина $\mathrm{pH}$ воды в стаканах составляла 7,5. Стаканы с растениями освещали сверху люминесцентными лампами холодного белого спектра (FSLYZ18RRT8/765) в течение 16 часов в сутки. Уровни освещенности на поверхности воды составляли 0,$5 ; 1 ; 2 ; 4 ; 6 ; 8$ и 10,2 кЛк, что соответствовало поверхностной плотности потока квантов 7; $14 ; 28 ; 56 ; 84$; 112 и 143 мкмоль $\cdot \mathrm{M}^{-2} \cdot \mathrm{c}^{-1}$. В первом оценочном эксперименте использовали более короткий диапазон уровней освещенности: 14; 28 ; 56 и 84 мкмоль $\cdot \mathrm{M}^{-2} \cdot \mathrm{c}^{-1}$. Темновой контроль создавали, оборачивая стакан алюминиевой 
фольгой со всех сторон. На каждый уровень освещенности приходился один стакан с растениями. Эксперимент проводили в термостатируемом помещении. Температура воды в стаканах составляла $21-22{ }^{\circ} \mathrm{C}$. Ежедневно стаканы поворачивали вокруг своей оси на $90^{\circ}$, чтобы выровнять освещенность побегов, измеряли температуру и $\mathrm{pH}$ воды, потери воды за счет испарения компенсировали дистиллированной водой (около 20 мл в сутки). Через 10 суток после посадки растения вынимали из ДО, измеряли длину побегов, длину корней, взвешивали после высушивания в темноте при комнатной температуре. Содержание влаги в биомассе побегов элодеи в начале экспериментов составило 90,8土0,6 \%. Для экстракции пигментов использовали по три побега на каждый уровень освещенности. Пигменты экстрагировали 96\%-м этиловым спиртом из целых побегов, высушенных в темноте при комнатной температуре до постоянного веса и растертых в порошок в керамической ступке. Оптическую плотность в экстрактах измеряли с помощью спектрофотометра (Specol 1300, Analytic Jena, Germany), концентрацию хлорофиллов $a$ (хл. $a)$ и $\sigma$ (хл. $\sigma$ ) и суммы каротиноидов (кар.) в экстракте рассчитывали согласно (Lichtenthaler, 1987; Lichtenthaler, Buschmann, 2001). Содержание металлов в воде измеряли с помощью ИСП-спектрометра (ICP-OES; iCAP 6300 Duospectrometer, Thermo Electron Manufacturing), как описано ранее (Zotina et al., 2015). Результаты измерений представлены как арифметические средние величины со стандартным отклонением.

Относительную скорость роста (ОСР) элодеи рассчитывали по формуле:

$$
\operatorname{OCP}\left(\text { сут }^{-1}\right)=\ln \left(\mathrm{X} / \mathrm{X}_{0}\right) / \mathrm{t},
$$

где $\mathrm{X}_{0}$ и $\mathrm{X}$ - сухой вес побегов в начале и конце эксперимента, $\mathrm{t}$ - длительность эксперимента в сутках.
Достоверность влияния светового фактора оценивали с помощью однофакторного анализа (ANOVA) с последующим LSD и HSD анализом на уровне значимости $p<0,05$ в программе Statistica 8.0. Коэффициенты вариабельности (CV, \%) индикаторных параметров элодеи рассчитывали как отношение стандартного отклонения среднего к средней величине параметра и выражали в \%.

\section{Результаты и обсуждение}

Фильтрованная водопроводная вода, использованная в экспериментах, может быть классифицирована как умеренно жесткая,

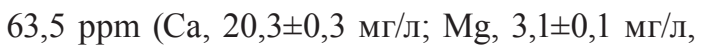
$\mathrm{n}=3)$. В воде зарегистрированы незначительные количества потенциально токсичных металлов и биогенных элементов (мг/л, $\mathrm{n}=3$ ): $\mathrm{Cu}-$ $0,03 \pm 0,01 ; \mathrm{Zn}-0,054 \pm 0,029 ; \mathrm{Pb}-0,001 \pm 0,000$; $\mathrm{P}-0,007 \pm 0,001 ; \mathrm{N}\left(\mathrm{NH}_{4}\right)-0,11 \pm 0,01$, не превышающие ПДК для питьевой воды. Содержание катионов жесткости в воде р. Енисей в месте отбора элодеи для эксперимента (18,2 мг/л Са и 2,8 мг/л $\mathrm{Mg}$ ) было аналогичным их содержанию в водопроводной воде.

За время эксперимента в темновом контроле листья на дистальной части побегов утратили пигменты, но побеги удлинились в среднем в 1,3 раза; на свету побеги удлинились в 1,7-2,4 раза по сравнению с их начальной длиной (рис. 1а). На большинстве побегов выросли боковые ответвления, вклад которых в суммарную длину побегов составлял до $28 \%$ в первом эксперименте и 11-24 \% - во втором. В темновом контроле корни на побегах элодеи не появились. Число и длина корней на побеге увеличивались при возрастании уровня освещенности до 14 мкмоль $\cdot \mathrm{M}^{-2} \cdot \mathrm{c}^{-1}$ (рис. 1б). При минимальной освещенности (7 мкмоль $\left.\cdot \mathrm{M}^{-2} \cdot \mathrm{c}^{-1}\right)$ в среднем выросло по 0,7 корня на побег, при более высокой - 1,2-1,8 корня на побег. 

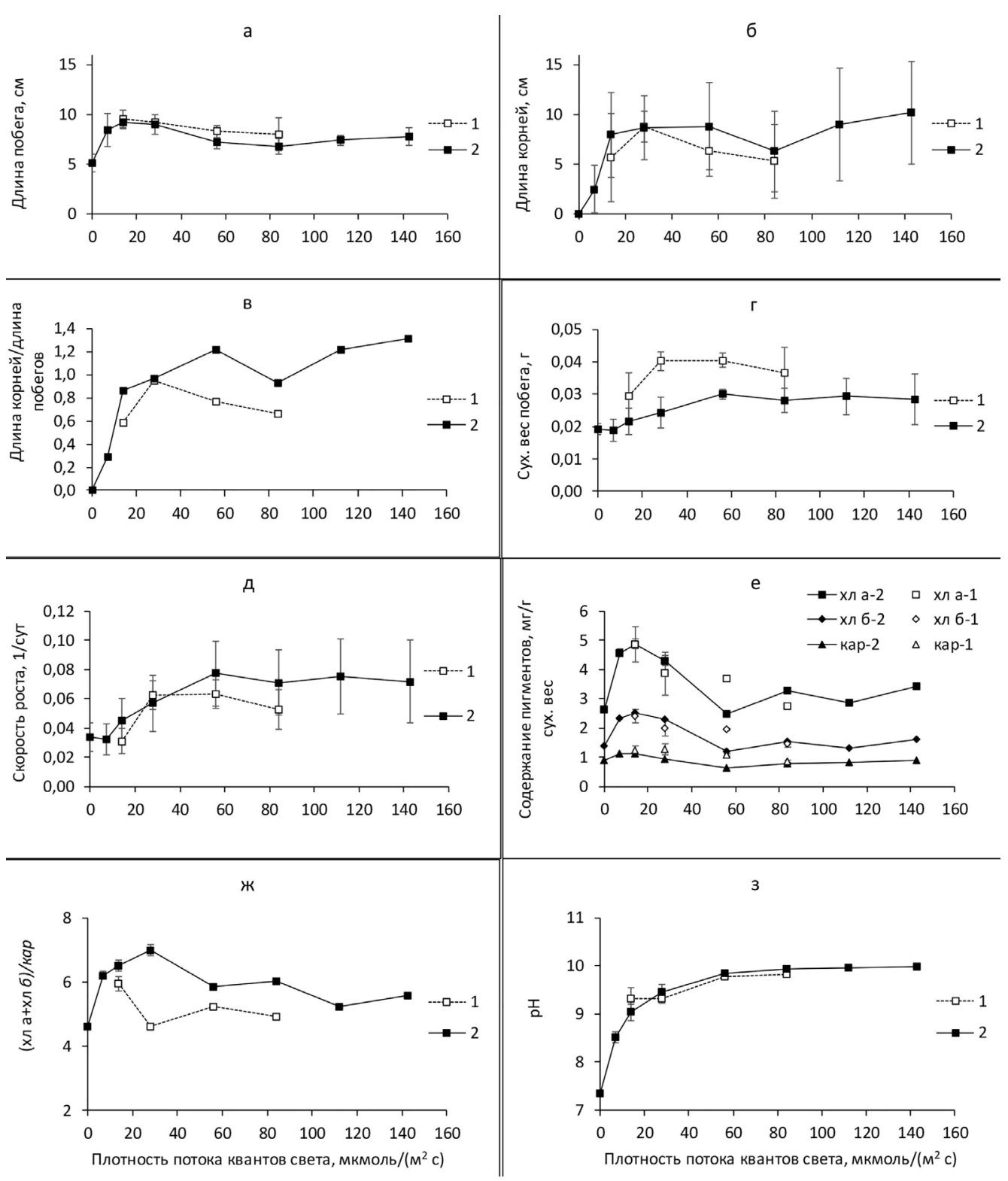

Рис. 1. Показатели роста и фотосинтетической активности E. canadensis в эксперименте в зависимости от плотности потока квантов света (среднее $\pm \mathrm{SD})$ : a - длина побега, см; 6 - суммарная длина корней на побеге, см; в - отношение длины корня к длине побега; г-сухой вес побега, г; д- относительная скорость роста биомассы побега, 1 ссут; е - содержание фотосинтетических пигментов в сухой биомассе побега, мг/г; ж - отношение содержания суммы хл. $a$ и хл. $\sigma$ к содержанию каротиноидов в сухой биомассе побега; 3 - средняя величина $\mathrm{pH}$ на 3-10 сутки эксперимента. Цифрами 1 и 2 обозначены эксперименты, проведенные с разницей в 2,5 недели. На каждом уровне освещенности использовалось по семь побегов элодеи, для анализа пигментов использовалось по три побега

Fig. 1. The growth and photosynthetic activity endpoints of E. canadensis in the experiment, depending on the density of the flux of light quanta (mean $\pm \mathrm{SD}$ ): a - shoot length, $\mathrm{cm}$; $\sigma$ - total length of roots on the shoot, $\mathrm{cm} ; \mathrm{B}-$ the ratio of root length to shoot length; $\Gamma$ - dry shoot weight, $g$; д - relative growth rate of shoot biomass, 1/day; $\mathrm{e}$ - the content of photosynthetic pigments in the dry shoot biomass, $\mathrm{mg} / \mathrm{g}$; $\%$ - the ratio of the content of the sum of chl. $a$ and chl. $b$ to the content of carotenoids in the dry shoot biomass; 3 - the average $\mathrm{pH}$ at 3-10 days of the experiment. Numbers 1 and 2 indicate experiments conducted with an interval of 2.5 weeks. At each irradiation level, seven shoots of Elodea were used; for analysis of pigments, three shoots were used 
Суммарная длина корней превышала длину побегов на 29-131 \% (рис. 1в). Прирост биомассы побегов за время эксперимента составил 36-117 \% (рис. 1г). Относительная скорость роста (ОСР) биомассы побегов вышла на насыщение при плотности потока квантов света 28 и 56 мкмоль $\cdot \mathrm{m}^{-2} \cdot \mathrm{c}^{-1}$ в первом и втором экспериментах, соответственно (рис. 1д). Более высокая ОСР биомассы побегов (до 0,077 $\pm 0,022$ сут $^{-1}$ ) зарегистрирована во втором эксперименте. Повышенное содержание фотосинтетических пигментов (хлорофиллов и каротиноидов) было зарегистрировано при плотности потока квантов 7-28 мкмоль $\cdot \mathrm{M}^{-2} \cdot \mathrm{c}^{-1}$, по сравнению с содержанием пигментов при более высоких уровнях освещенности (рис. 1е). Отношение содержания суммы хлорофиллов к содержанию каротиноидов было также выше при более низкой освещенности (рис. 1ж). Величина $\mathrm{pH}$ воды достигла стационарного равновесного значения на вторые-третьи сутки эксперимента при всех уровнях освещенности, что позволило нам усреднить величины pH в период с третьих по восьмые сутки. Полученная таким образом равновесная величина $\mathrm{pH}$, которую можно рассматривать как косвенный показатель интенсивности фотосинтеза элодеи, вышла на насыщение при плотности потока квантов света в диапазоне 28-56 мкмоль $\cdot \mathrm{M}^{-2} \cdot \mathrm{c}^{-1}$ (рис. 13).

Относительная скорость роста биомассы побегов элодеи достигла светового насыщения при интенсивности светового потока между 28 и 56 мкмоль $\cdot \mathrm{M}^{-2} \cdot \mathrm{c}^{-1}$ (рис. 1д), что соответствует данным, полученным в работе (Madsen, Sand-Jensen, 1994). В этом же диапазоне освещенности наблюдался выход на насыщение уровня $\mathrm{pH}$ (рис. 13). Содержание фотосинтетических пигментов в побегах элодеи статистически значимо $(p<0,05)$ возрастало с увеличением светового потока и достигло максимума при 14 мкмоль $\cdot \mathrm{M}^{-2} \cdot \mathrm{c}^{-1}$. При дальнейшем повышении уровня освещенности содержание пигментов снизилось и вышло на стационарный уровень при освещенности 56 мкмоль $\cdot \mathrm{M}^{-2} \cdot \mathrm{c}^{-1}$ (рис. 1е). Также в диапазоне освещенности 7-28 мкмоль $\cdot \mathrm{M}^{-2} \cdot \mathrm{c}^{-1}$ наблюдалось статистически значимое $(p<0,05)$ увеличение длины побегов элодеи (рис. 1а). Увеличение длины побегов и содержания фотосинтетических пигментов при относительно низких освещенностях $\left(7,14\right.$ и 28 мкмоль $\left.\cdot \mathrm{m}^{-2} \cdot \mathrm{c}^{-1}\right)$ в наших экспериментах мы можем объяснить недостатком световой энергии, принимая во внимание снижение вышеуказанных параметров при более высоких уровнях освещенности (56 мкмоль $\cdot \mathrm{m}^{-2} \cdot \mathrm{c}^{-1}$ и более) (рис. 1a,e). Таким образом, уровень освещенности около 60 мкмоль $\cdot \mathrm{M}^{-2} \cdot \mathrm{c}^{-1}$ можно считать близким к оптимуму для элодеи канадской, и запасенной при этом энергии достаточно для нормального роста и развития растения. Наше предположение согласуется с данными, опубликованными в работе (Lichtenthaler et al., 1981), где показано, что при достаточном уровне освещенности содержание хлорофиллов и отношение содержания хлорофиллов к содержанию каротиноидов в листьях растений снижаются.

При биотестировании донных отложений вес побегов считается основным индикатором роста погруженных макрофитов, в том числе в силу наименьшей вариабельности этого показателя по сравнению с другими показателями их роста (Knauer et al., 2006; Feiler et al., 2013). Из числа исследованных нами физиологических индикаторов элодеи канадской длина побега, вес побега и содержание хл. $a$ имели близкую по величине вариабельность (табл.), приемлемую для индикаторных параметров при биотестировании (Knauer et al., 2006; Feiler et al., 2013). Вариабельность 
Таблица. Вариабельность (CV, \%) индикаторных показателей роста и фотосинтеза E. canadensis в эксперименте с восемью уровнями освещенности в диапазоне $0-143$ мкмоль $\cdot \mathrm{M}^{-2} \cdot \mathrm{c}^{-1}$

Table. Variability (CV, \%) of indicator endpoints of growth and photosynthesis of E. canadensis in an experiment with eight levels of irradiance in the range of $0-143 \mu \mathrm{mol} \cdot \mathrm{m}^{-2} \cdot \mathrm{s}^{-1}$

\begin{tabular}{ccc}
\hline Индикатор & \multicolumn{2}{c}{ Коэффициент вариабельности, CV, \% } \\
\cline { 2 - 3 } & Диапазон величин & Среднее $\pm \mathrm{SD}(\mathrm{n}=8)$ \\
\hline Длина побега & $11,1-25,4$ & $16,7 \pm 5,1$ \\
Длина корня & $36,9-97,5$ & $59,5 \pm 19,1$ \\
Вес побега & $4,7-27,7$ & $17,4 \pm 6,9$ \\
Содержание хл. $a$ & $7,3-41,3$ & $18,0 \pm 12,2$ \\
\hline
\end{tabular}

длины корней была в три раза больше, чем вариабельность других физиологических показателей элодеи канадской. Другие авторы также отмечают большую чувствительность длины корней к качеству окружающей среды (Arts et al., 2008; Zotina et al., 2015), по сравнению с показателями роста побегов, а также большую вариабельность показателей роста корней.

\section{Заключение}

Анализ реакции показателей роста побегов и корней элодеи канадской, а также содержания и соотношения фотосинтетических пигментов в биомассе побегов растения на изменение уровня освещенности позволяет выделить диапазон светового потока от 56 до 143 мкмоль $\cdot \mathrm{m}^{-2} \cdot \mathrm{c}^{-1}$, в котором не происходит лимитирования и ингибирования роста и фотосинтеза элодеи канадской. Следовательно, уровень освещенности из выделенного диапазона рекомендуется использовать в модельной системе, предложенной для биотестирования донных отложений с использованием элодеи канадской в качестве индикатора.

\section{Благодарности / Acknowledgements}

Авторы благодарят О.В. Анищенко (Институт биофизики СО РАН) за химический анализ проб воды, а также анонимных рецензентов за ценные замечания и предложения.

The authors are grateful to O.V. Anishchenko (Institute of Biophysics SB RAS) for chemical analysis of water samples and to anonymous reviewers for valuable comments and suggestions.

\section{Список литературы / References}

Болсуновский А.Я., Муратова Е.Н., Суковатый А.Г., Пименов А.В., Санжараева Е.А., Зотина Т.А., Седельникова Т.С., Паньков Е.В., Корнилова М.Г. (2007) Радиоэкологический мониторинг реки Енисей и цитогенетические характеристики водного растения Elodea canadensis. Радиационная биология. Радиоэкология, 47(1): 63-73 [Bolsunovsky A.Ya., Muratova E.N., Sukovaty A.G., Pimenov A.V., Sanzharaeva E.A., Zotina T.A., Sedelnikova T.S., Pankov E.V., Kornilova M.G. (2007) Radioecological monitoring of the Yenisei River and cytological characterization of a submerged aquatic plant Elodea canadensis. Radiation Biology. Radioecology [Radiacionnaya biologiya. Radioekologiya], 47(1): 63-73 (in Russian)] 
Зотина Т.А. (2013) Находка бразильской элодеи Egeria densa Planch. (Hydrocharitaceae) в реке Енисей. Turczaninowia, 16(3): 60-63 [Zotina T.A. (2013) Finding of Brazilian elodea Egeria densa Planch. (Hydrocharitaceae) in the Yenisei River. Turczaninowia, 16(3): 60-63 (in Russian)]

Зотина Т.А. (2014) Фитомасса и видовое разнообразие макрофитной растительности в среднем течении р. Енисей. Журнал Сибирского федерального университета. Биология, 7(1): 73-86 [Zotina T.A. (2014) Phytomass and specific diversity of macrophyte vegetation in the middle reach of the Yenisei River. Journal of Siberian Federal University. Biology, 7(1): 73-86 (in Russian)]

Arts G.H.P., Belgers J.D.M., Hoekzema C.H., Thissen J.T.N.M. (2008) Sensitivity of submersed freshwater macrophytes and endpoints in laboratory toxicity tests. Environmental Pollution, 153(1): 199-206

Brain R.A., Hoberg J., Hosmer A.J., Wall S.B. (2012) Influence of light intensity on the toxicity of atrazine to the submerged freshwater aquatic macrophyte Elodea canadensis. Ecotoxicology and Environmental Safety, 79: 55-61

Eller F., Alnoee A.B., Boderskov T., Guo W.-Y., Kamp A.T., Sorrell B.K., Brix H. (2015) Invasive submerged freshwater macrophytes are more plastic in their response to light intensity than to the availability of free $\mathrm{CO}_{2}$ in air-equilibrated water. Freshwater Biology, 60(5): 929-943

Feiler U., Höss S., Ahlf W., Gilberg D., Hammers-Wirtz M., Hollert H., Meller M., NeumannHensel H., Ottermanns R., Seiler T.B., Spira D., Heininger P. (2013) Sediment contact tests as a tool for the assessment of sediment quality in German waters. Environmental Toxicology and Chemistry, 32(1): 144-155

Girling A.E., Pascoe D., Janssen C.R., Peither A., Wenzel A., Schäfer H., Neumeier B., Mitchell G.C., Taylor E.J., Maund S.J., Lay J.P., Jüttner I., Crossland N.O., Stephenson R.R., Persoone G. (2000) Development of methods for evaluating toxicity to freshwater ecosystems. Ecotoxicology and Environmental Safety, 45(2): 148-176

Knauer K., Vervliet-Scheebaum M., Dark R.J., Maund S.J. (2006) Methods for assessing the toxicity of herbicides to submersed aquatic plants. Pest Management Science, 62(8): 715-722

Koca F.D., Yilmaz D.D., Duman F., Ocsoy I. (2018) Comparison of phytotoxic effects of biosynthesised copper oxide nanoparticle and ionic copper on Elodea canadensis. Chemistry and Ecology, 34(9): 839-853

Krems P., Rajfur M., Wacławek M., Kłos A. (2013) The use of water plants in biomonitoring and phytoremediation of waters polluted with heavy metals. Ecological Chemistry and Enginering $S$, 20(2): 353-370

Lichtenthaler H.K., Buschmann C. (2001) Chlorophylls and carotenoids: measurement and characterization by UV-VIS spectroscopy. Current Protocols in Food Analytical Chemistry, 1(1): F4.3.1F4.3.8

Lichtenthaler H.K.(1987) Chlorophylls and carotenoids: pigments of photosynthetic biomembranes. Methods in Enzymology, 148: 350-382

Lichtenthaler H.K., Buschmann C., Doll M., Fietz H.J., Bach T., Kozel U., Meier D., Rahmsdorf U. (1981) Photosynthetic activity, chloroplast ultrastructure, and leaf characteristics of high-light and lowlight plants and of sun and shade leaves. Photosynthesis Research, 2(2): 115-141

Madsen T.V., Sand-Jensen K. (1994) The interactive effects of light and inorganic carbon on aquatic plant growth. Plant, Cell and Environment, 17(8): 955-962 
McGregor E.B., Solomon K.R., Hanson M.L. (2008) Effects of planting system design on the toxicological sensitivity of Myriophyllum spicatum and Elodea canadensis to atrazine. Chemosphere, 73(3): 249-260

Medvedeva M.Yu., Bolsunovsky A.Ya., Zotina T.A. (2014) Cytogenetic abnormalities in aquatic plant Elodea canadensis in anthropogenic contamination zone of Yenisei River. Contemporary Problems of Ecology, 7(4): 422-432

Muratova E.N., Goryachkina O.V., Kornilova M.G., Pimenov A.V., Sedelnikova T.S., Bolsunovsky A.Ya. (2014) Cytogenetic studies on submerged plants from the Yenisei River area in the zone of radioactive contamination. Biology Bulletin, 41(5): 461-467

Riis T., Olesen B., Clayton J.S., Lambertini C., Brix H., Sorrell B.K. (2012) Growth and morphology in relation to temperature and light availability during the establishment of three invasive aquatic plant species. Aquatic Botany, 102: 56-64

Samecka-Cymerman A., Kempers A.J. (2003) Biomonitoring of water pollution with Elodea canadensis. A case study of three small Polish rivers with different levels of pollution. Water, Air, and Soil Pollution, 145: 139-153

Wolff B., Senger H. (1991) Adaptation of the photosynthetic apparatus of aquatic higher-plants to various light-conditions. Journal of Plant Physiology, 138(3): 358-362

Zotina T., Medvedeva M., Trofimova E., Alexandrova Yu., Dementyev D., Bolsunovsky A. (2015) Chromosomal abnormalities in roots of aquatic plant Elodea canadensis as a tool for testing genotoxicity of bottom sediments. Ecotoxicology and Environmental Safety, 122: 384-391

Zotina T.A., Trofimova E.A., Bolsunovsky A.Ya., Anishenko O.V. (2014) Experimental estimation of the possible use of submersed macrophytes for biotesting bottom sediments of the Yenisei River. Contemporary Problems of Ecology, 7(4): 410-421 